\title{
Effects of melatonin implants in ewe lambs
}

\author{
D. J. Kennaway and T. A. Gilmore \\ Department of Obstetrics and Gynaecology, University of Adelaide, The Queen Elizabeth Hospital, \\ Woodville Road, Woodville, South Australia 5011, Australia
}

\begin{abstract}
Summary. Sixteen pinealectomized and 19 unoperated ewes were exposed to constant light for about 4 weeks before and 4 weeks after lambing. Five ewe lambs born to pinealectomized ewes were implanted s.c. with melatonin sachets and 6 ewe lambs implanted with empty sachets. The 6 ewe lambs born to unoperated dams received empty implants. Ewes and lambs were then returned to the field. Puberty (determined by weekly progesterone analysis) was significantly delayed $(P<0.05)$ in 4 of the 5 melatonin-treated ewe lambs; mean pubertal age of ewes with empty implants was 44 weeks of age compared to $45,63,72,>72,>72$ weeks of age for the melatonin-treated animals. Prolactin levels were decreased in the ewes with empty implants in autumn, coincident with the period of cyclic ovarian activity. No significant decrease in prolactin was observed in autumn in melatonin-treated lambs. Growth was not affected by melatonin treatment. These results indicate a role of the pineal gland and melatonin in the control of puberty in sheep.
\end{abstract}

\section{Introduction}

The age at which puberty occurs in ewe lambs is determined in part by the season of birth and in part by prevailing photoperiod conditions (Foster, 1981). Animals born in autumn or winter have puberty delayed until the following autumn, corresponding to the time of onset of puberty of younger, spring-born lambs. Two explanations for this phenomenon have been proposed. The autumn-born ewe lambs may achieve full sexual competence at the same age as spring-born animals, but the expression of this maturity may be inhibited by the same factors involved in suppression of ovarian activity in mature ewes during anoestrus (Land, 1978; Foster, 1981). An alternative view is that the sexual development is retarded until the following autumn by photoperiodic and other environmental factors (Foster, 1981). A common feature of these two hypotheses is the implication of photoperiodic repression of ovarian activity during spring and summer. Foster (1981) has shown that the prepubertal ewe is extremely sensitive to the negative feedback action of oestradiol on $\mathrm{LH}$ release. Furthermore, autumn-born animals could be induced by photoperiod manipulation to become less sensitive to oestradiol feedback and commence ovarian activity at an early age (Foster, 1981).

The link between photoperiod and seasonal variations in reproductive competence in adult sheep is now thought to involve the pineal-melatonin system (Kennaway, Gilmore \& Seamark, 1982a). The role of the pineal gland in prepubertal sheep is not yet established. Pinealectomy of prepubertal sheep does not affect growth rate (Brown \& Forbes, 1980) but does alter prolactin response to photoperiod (Brown $\&$ Forbes, 1980). No studies are available on the effect of pineal manipulation on the timing of puberty in ewes. Treatment of adult ewes with melatonin implants results in decreased prolactin secretion, apparently mimicking the prolactin changes observed when the daily photoperiod is shortened (Kennaway et al., 1982b; Kennaway, Dunstan, Gilmore \& 
Seamark, 1983a). We have therefore investigated the effects of melatonin treatment upon the development of ovarian cyclicity, and prolactin and melatonin secretion in ewe lambs from 4 weeks of age. Pinealectomized and unoperated dams were used to determine whether puberty onset is influenced by the maternal pineal gland.

\section{Materials and Methods}

The experiment was conducted at the Mortlock Experiment Station, Mintaro, South Australia, between January 1981 and October 1982. Sixteen 5-year-old Saxon Merino $\times$ Border Leicester ewes that had been pinealectomized previously (at age 6 months) according to the procedure of Kennaway, Obst, Dunstan \& Friesen (1981a) and 19 unoperated ewes were mated to Dorset rams in early January 1981. At 4 weeks before lambing, the ewes were moved from the field to an animal house where they were kept in groups of 8-9 ewes per pen. The ewes were maintained during this period on a diet of alfalfa chaff and oats. The lights (GEC-Multivapor, providing in excess of 1500 lux at sheep's eye level) operated continuously until the lambs were 1-4 weeks old to suppress melatonin production before treatment. Six ewe lambs were born to unoperated ewes (Group C) and 11 ewe lambs were born to pinealectomized dams (Group P). The 22 rams born in this experiment will be the subjects of a future communication. Melatonin sachets were prepared from Silastic medical-grade sheeting $(0.125 \mathrm{~cm}$ thick: Dow Corning, Midland, Michigan, U.S.A.) as previously reported (Kennaway et al., 1982b). Five ewe lambs born to pinealectomized dams were each implanted with one melatonin sachet subcutaneously on the back at 3-4 weeks of age and a second sachet at 13-14 weeks (Group Pm). Empty implants were placed in the remaining 12 lambs (Group Pe and Group Ce).

The 35 ewes with their lambs were randomly allocated to adjoining paddocks. The ram lambs were vasectomized before they reached puberty. All lambs were weaned at 16 weeks of age and shorn at 20 and 72 weeks. Every Tuesday for 69 weeks the flocks were removed to a stock yard using a sheep dog, and a single blood sample $(10: 00 \mathrm{~h}-11: 30 \mathrm{~h})$ was taken by venepuncture. The plasma fraction was prepared and frozen. At 35-36 weeks of age the ewe lambs were placed in single pens in an open shed and hourly blood samples were taken during late afternoon and throughout the night in dim red light.

Progesterone was assayed by RIA (Janson, Amato, Weiss, Ralph \& Seamark, 1978). Sensitivity of the assay (McIntosh \& McIntosh, 1980) was in the range $0.5-0.8 \mathrm{nmol} / 1$, and intra- and interassay coefficients of variation were $<12 \%$ at $7 \mathrm{nmol} / 1$.

Melatonin was assayed by RIA (Kennaway et al., 1982a). Sensitivity was less than $86 \mathrm{pmol} / 1$ and intra- and inter-assay coefficients of variation at $0.63 \mathrm{nmol} / 1$ were $12 \%$ and $17 \%$ respectively.

Prolactin was assayed by RIA (Kennaway et al., 1981a) using NIH-P-S13 as standard. Sensitivity was $<3 \mathrm{ng} / \mathrm{ml}$ and intra- and inter-assay coefficients of variation through the range 10 $300 \mathrm{ng} / \mathrm{ml}$ were $<10 \%$.

\section{Results}

The initial linear growth-rate phase and subsequent body weight fluctuations of the lambs were very similar for lambs in Groups Pm, Pe and Ce (Text-fig. 1). The greater range in weights in Group Pm is due to this group having both the heaviest and lightest animals in the experiment. The fleece weights at 20 and 72 weeks were not significantly different (data not shown).

The weekly blood samples were assayed for progesterone and puberty was defined as having occurred when levels in excess of $2 \mathrm{nmol} / 1$ were measured. On this basis cyclic ovarian activity was judged to have begun in ewe lambs in Groups $\mathrm{Ce}$ and Pe between 39 and 45 weeks of age (Text-fig. 1; Table 1). The lambs in Group Pm had significantly delayed onset of puberty $(P<0.05$, Mann- 
(4) 476ua|人eo
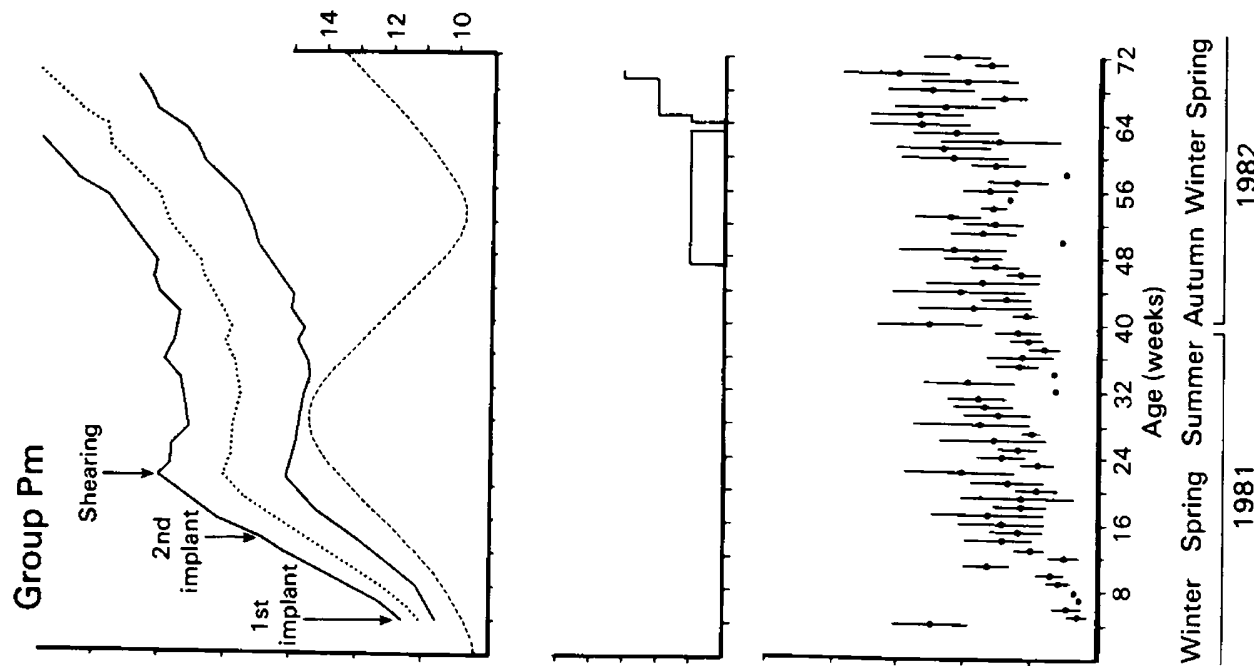

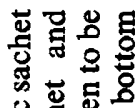
莺兽焉

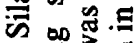

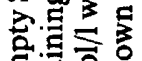
क U
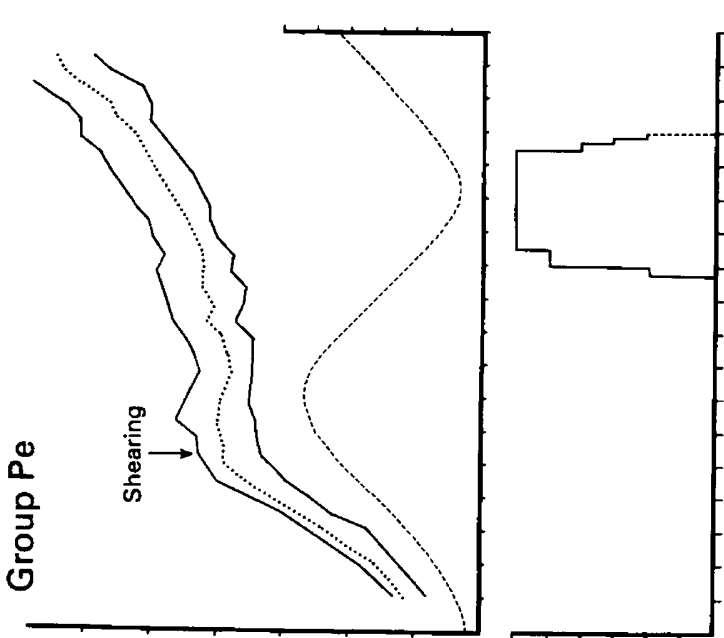

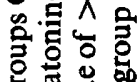

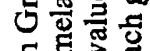
E $\mathrm{E}>$
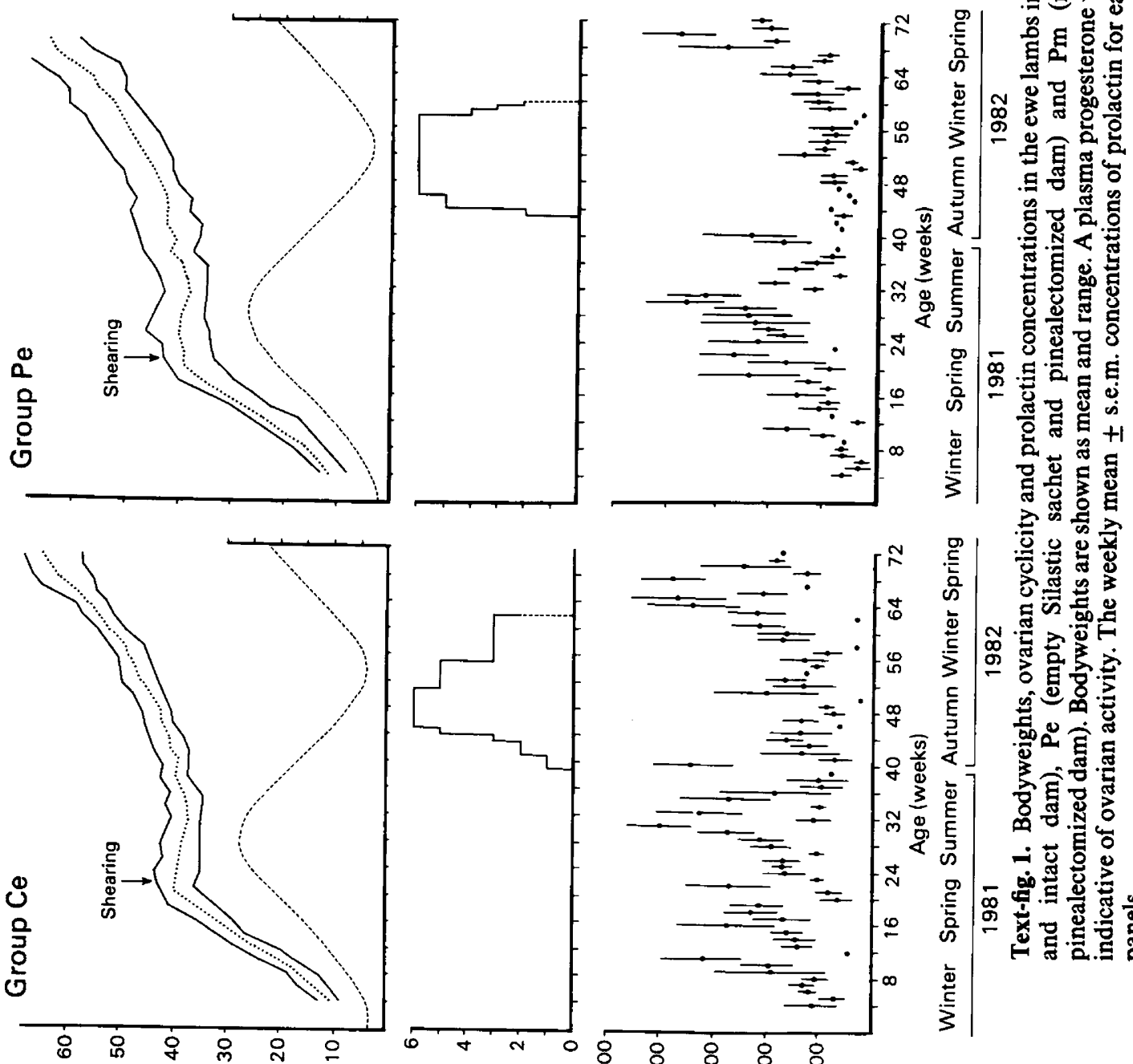

(6) IM Apog

के

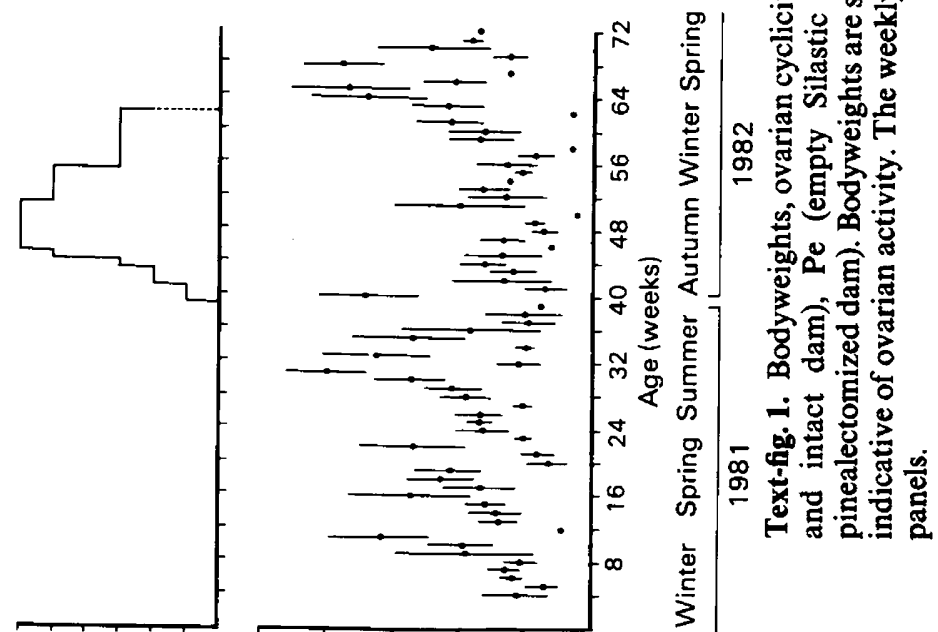


Whitney U test). However, Ewe 496 in Group Pm showed onset of puberty at an age comparable with that of untreated sheep ( 45 weeks). The Group Pm lambs had body weights in excess of $30 \mathrm{~kg}$ at the time of onset of puberty in the other groups, indicating that low body weight was not a major contributing factor in the delayed puberty. The breeding season of the lambs in Groups $\mathrm{Ce}$ and $\mathrm{Pe}$ terminated at 50-60 weeks of age, representing breeding periods of 6-23 weeks duration. Two ewe lambs from each of Groups $\mathrm{Ce}$ and Pe became pregnant at the time of puberty and the subsequent pregnancy and delivery of live lambs were normal. The lamb in Group Pm that showed cyclic progesterone fluctuations at 45 weeks ceased ovarian activity at 61 weeks. This lamb and 2 others in Group Pm had begun showing cyclic changes in progesterone levels by 72 weeks of age (i.e. during spring).

Table 1. The age at puberty and anoestrus and weight at puberty in ewe lambs in Groups $\mathrm{Ce}, \mathrm{Pe}$ and $\mathrm{Pm}$

\begin{tabular}{lcccc}
\hline Group & $N$ & $\begin{array}{c}\text { Age at puberty } \\
\text { (weeks) }\end{array}$ & $\begin{array}{c}\text { Age at anoestrus } \\
\text { (weeks) }\end{array}$ & $\begin{array}{c}\text { Weight at puberty } \\
\text { (kg) }\end{array}$ \\
\hline $\mathrm{Ce}$ & 6 & $42 \pm 0.8$ & $55 \pm 2 \cdot 5$ & $40 \pm 1 \cdot 0$ \\
$\mathrm{Pe}$ & 6 & $44 \pm 0.8$ & $58 \pm 0 \cdot 7$ & $42 \pm 1 \cdot 8$ \\
$\mathrm{Pm}$ & 5 & $45,63,72,>72,>72$ & $61,>72,>72,>72,>72$ & $45,50,58,>72,>76$ \\
\hline
\end{tabular}

The age at puberty was determined from the first weekly blood sample having a progesterone concentration $>2 \mathrm{nmol} / 1$.

Values are mean \pm s.e.m. except for Group $\mathrm{Pm}$ for which individual values are given.

The prolactin concentrations in the weekly blood samples were characterized by large variations between individuals and between weeks (Text-fig. 1). This was due in part to the herding of animals into the stock yards and the use of a single weekly blood sample. To minimize the effect of these variations for statistical purposes, the study was divided into 13-week periods corresponding to winter, spring and summer 1981, autumn, winter and spring 1982. The median levels were calculated for these periods and analysed for seasonal interactions by the Friedman nonparametric 2-way analysis of variance and Wilcoxon's critical range test (Colquhoun, 1971). The prolactin values were highest in spring and summer 1981 and spring $1982(P<0.05)$ and lowest in autumn in Groups $\mathrm{Ce}$ and $\mathrm{Pe}(P<0.05)$. The ewe lambs in Group $\mathrm{Pm}$ had the lowest prolactin concentrations in winter 1981 and the highest in spring 1982, with no autumn/winter decrease $(P>$ $0 \cdot 05$ ). There was no significant difference between the three groups in autumn (Kruskal-Wallis one way analysis of variance).

The melatonin implants in Group Pm produced peripheral blood melatonin levels of $1.3 \pm 0.09$ $\mathrm{nmol} / \mathrm{l}$ (mean \pm s.e.m.) soon after placement, decreasing over the ensuing 10 weeks to $0 \cdot 36 \pm 0 \cdot 11$ $\mathrm{nmol} / \mathrm{l}$. The placement of a second sachet raised the melatonin levels to $0 \cdot 56 \pm 0 \cdot 1 \mathrm{nmol} / 1$ which is comparable with normal night levels in the control lambs. This level was maintained for the remainder of the study. Daytime melatonin levels in Groups $\mathrm{Pe}$ and $\mathrm{Ce}$ remained below the sensitivity of the assay $(<86 \mathrm{pmol} / \mathrm{l})$ throughout the experiment. At 36 weeks all 3 groups of lambs showed a nocturnal increment of melatonin in excess of $0.34 \mathrm{nmol} / 1$ (data not shown).

\section{Discussion}

Lambs implanted with melatonin sachets showed a considerable delay in the onset of puberty. In adult ewes melatonin implants simulate short daylength, decreasing prolactin levels (Kennaway $e t$ al., 1982b, 1983a) and advancing the breeding season (D. J. Kennaway, E. A. Dunstan, T. A. Gilmore \& R. F. Seamark, unpublished results). On this basis we had predicted that melatonintreated lambs would undergo early puberty and maintain low circulating prolactin levels. Melatonin treatment did affect the development of the circannual prolactin rhythm but failed to 
depress the prolactin levels. The stress associated with the weekly blood sampling may have masked any effect of melatonin on basal prolactin secretion. Walton, McNeilly, McNeilly \& Cunningham (1977) have proposed that low prolactin levels are required for the onset and maintenance of ovarian function. The true significance of the decreased autumn levels of prolactin is, however, unclear since apparently normal ovarian cyclicity persists during periods of elevated prolactin levels (Kennaway, Sanford, Godfrey \& Friesen, 1983b). Future experiments with sheep maintained in controlled environments and utilizing multiple blood sampling may clarify the question of prolactin suppression by melatonin in young lambs.

The melatonin levels achieved during the first few weeks of the study were considerably higher than reported previously in adult ewes with similar sachets (Kennaway et al., 1982b), but gradually decreased over a 10-week period and then produced stable levels. The second implant was used to raise the melatonin levels to normal night-time levels. The decrease in circulating melatonin observed is due to the rapid weight gain and the maturation of the metabolic pathways for melatonin in the lamb (J. D. Marszal, D. J. Kennaway \& R. F. Seamark, unpublished results). Similar observations have been made recently in neonatal rats (Weinberg, 1981).

The mechanisms by which the melatonin implants delayed puberty are unknown. In adult ewes there is no feedback of melatonin upon its own secretion (Kennaway et al., 1982a), and this was confirmed in the current study. The maintenance of high basal melatonin levels with the implants may have impaired the development of melatonin receptors (Cardinali, Vacas \& Estevez-Boyer, 1979 ) or the circadian rhythm in melatonin receptor number (Vacas \& Cardinali, 1979). Yellon \& Foster (1982) have shown that normal puberty onset in sheep can occur only after exposure to at least 17 weeks of long daylength. The short duration of melatonin secretion during long daylength may allow the establishment of a 'melatonin-sensitive phase' during the light period in tissues responsive to melatonin. The constant high melatonin levels resulting from the implants would delay considerably (but apparently not permanently) the establishment of this melatonin-sensitive phase. The eventual initiation of puberty observed in this experiment may reflect a raising of the threshold of sensitivity to melatonin in the target tissues such that the nocturnal melatonin increase, superimposed on the high basal melatonin levels, was eventually interpreted as arising from short daylength.

The influence of maternal pineal function upon puberty was also investigated in this study since maternal melatonin is rapidly transferred across the placenta and possibly exposes the fetus to rhythmic melatonin levels (Kennaway, Matthews \& Seamark, 1981b). Pinealectomized and unoperated dams kept in constant light for 4 weeks before and 4 weeks after birth produced lambs that attained puberty at the same age. It is likely that maternal influences upon puberty (if any) operate during the last 4 weeks of gestation and in this experiment would have been masked by the suppression of melatonin production by the constant light. A role of the fetus in the establishment of pineal rhythms cannot be excluded because the fetal pineal gland can produce melatonin before parturition (Kennaway, Matthews, Seamark, Phillipou \& Schilthuis, 1977). It is more likely that light perception in the early neonatal period plays a role in puberty onset. Constant light during early neonatal development totally inhibits melatonin secretion (D. J. Kennaway \& T. A. Gilmore, unpublished results) but, as shown in the present experiment, does not result in permanent impairment of rhythmic pineal melatonin secretion or the systems involved in puberty onset. Sexual maturity did occur, the prolactin circannual rhythm developed and onset of ovarian activity coincided with the low prolactin levels.

If the neonatal pineal is involved in determining the time of puberty we would expect to find some confirmation of its importance in previous experiments involving changes in photoperiod and neonatal pinealectomy. Radford (1961), Smith (1967) and Ducker, Bowman \& Temple (1973) all studied the onset of puberty following various photoperiodic manipulations, but with equivocal results. Unfortunately, in all of these experiments the light treatments were imposed at 2-3 months of age, after previous exposure to natural daylength changes. Photoperiodic entrainment during this period may have reduced the effectiveness of subsequent treatments. The animals studied by 
Radford (1961) were housed in an open shed and given supplemental lighting of low intensity at night; thus they experienced a daily change in light intensity together with a seasonal component. When Yellon \& Foster (1982) raised lambs from birth in short daylength they observed a considerable delay in puberty onset. To date the only experiments utilizing pinealectomy have involved observations of growth rate and prolactin fluctuations (Forbes, 1975; Brown \& Forbes, 1980 ), and in both studies the pineal glands were removed at 5-6 months of age. To test properly the role of the neonatal pineal gland in puberty, those treatments thought to influence the gonadal axis should be started at birth, before rhythmic pineal function can begin in the lambs.

We thank Dr R. F. Seamark for his enthusiastic support during this study and $\mathrm{Mr} \mathbf{P}$. Geytenbeek, Mr P. Van Beusichem, Mr P. Steele, and Mr P. Attick of the Waite Institute and Mortlock Experiment station for excellent care of the animals; Miss A. Diamanti, Miss T. Lloyd, Mrs M. Kolo, Miss W. Jones, Miss L. Hourigan and Miss S. Hodson for technical assistance; Dr H. G. Friesen for antiprolactin serum; NIAMMD for the supply of ovine prolactin; and Mr P. Turner, Osram-GEC Australia, for the generous loan of the multivapour lamps. This work was supported by a grant from the National Health and Medical Research Council of Australia.

\section{References}

Brown, E.B. \& Forbes, J.M. (1980) Diurnal variations of plasma prolactin in growing sheep under two lighting regimes and the effect of pinealectomy. J. Endocr. 84, 9I-99.

Cardinali, D.P., Vacas, M.I. \& Estevez-Boyer, E. (1979) Specific binding of melatonin in bovine brain. Endocrinology 105, 437-441.

Colquhoun, D. (1971) Lectures on Biostatistics. Oxford University Press, London.

Ducker, M.J., Bowman, J.C. \& Temple, A. (1973) The effect of constant photoperiod on the expression of oestrus in the ewe. J. Reprod. Fert., Suppl. 19, 143150.

Forbes, J.M. (1975) Effect of pinealectomy on growth and plasma prolactin in sheep at two daylengths. Acta endocr., Copenh., Suppl. 199, 121, Abstr.

Foster, D.L. (1981) Mechanism for delay of first ovulation in lambs born in the wrong season (fall). Biol. Reprod. 25, 85-92.

Janson, P.O., Amato, F., Weiss, T.J., Ralph, M.M. \& Seamark, R.F. (1978) On the isolated perfused sheep ovary as a model for the study of ovarian function. Fert. Steril. 30, 230-236.

Kennaway, D.J., Matthews, C.D., Seamark, R.F., Phillipou, G. \& Schilthuis, M. (1977) On the presence of melatonin in pineal glands and plasma of foetal sheep. J. Steroid Biochem. 8, 559-563.

Kennaway, D.J., Obst, J.M., Dunstan, E.A. \& Friesen, H.G. (1981a) Ultradian and seasonal rhythms in plasma gonadotropins, prolactin, cortisol and testosterone in pinealectomized rams. Endocrinology 108, $639-646$.

Kennaway, D.J., Matthews, C.D. \& Seamark, R.F. (1981b) Pineal function in pregnancy: studies in sheep and man. In Pineal Function, pp. 123-136. Eds R. F. Seamark \& C. D. Matthews. Elsevier, Amsterdam.
Kennaway, D.J., Gilmore, T.A. \& Seamark, R.F. (1982a) Effect of melatonin feeding on serum prolactin and gonadotropin levels and the onset of seasonal estrous cyclicity in sheep. Endocrinology 110, 17661772.

Kennaway, D.J., Gilmore, T.A. \& Seamark, R.F. (1982b) Effects of melatonin implants on the circadian rhythm of plasma melatonin and prolactin in sheep. Endocrinology 110, 2186-2188.

Kennaway, D.J., Dunstan, E.A., Gilmore, T.A. \& Seamark, R.F. (1983a) Effects of shortened daylength and melatonin treatment on plasma prolactin and melatonin levels in pinealectomised and sham operated ewes. Anim. Reprod. Sci. 5, 287-294.

Kennaway, D.J., Sanford, L.M., Godfrey, B. \& Friesen, H.G. (1983b) Patterns of progesterone, melatonin and prolactin secretion in ewes maintained in four different photoperiods. J. Endocr. 97, 229-242.

Land, R.B. (1978) Reproduction in young sheep. Some genetic and environmental sources of variation. $J$. Reprod. Fert. 52, 427-436.

McIntosh, J.E.A. \& McIntosh, R.P. (1980) Mathematical modelling and computers in endocrinology. Monogr. Endocrinol. 16, 168.

Radford, H.M. (1961) Photoperiodism and sexual activity in merino ewes. I. The effect of continuous light on the development of sexual activity. Aust. J. agric. Res. 12, 139-145.

Smith, I.D. (1967) The effect of constant long daily photoperiod upon the onset of puberty in ewes. $J$. agric. Sci., Camb. 69, 43-45.

Vacas, M.I. \& Cardinali, D.P. (1979) Diurnal changes in melatonin binding sites of hamster and rat brains. Correlation with neuro endocrine responsiveness to melatonin. Neurosci. Lett. 15, 259-263.

Walton, J.S., McNeilly, J.R., McNeilly, A.S. \& Cunningham, F.J. (1977) Changes in concentrations of follicle 
stimulating hormone, luteinizing hormone, prolactin and progesterone in the plasma of the ewes during the transition from anoestrus to breeding activity. $J$. Endocr. 75, 127-136.

Weinberg, U. (1981) Evidence that melatonin retention by the neonatal rat is greatly increased as compared to the adult: a novel biochemical mechanism. Brain Res. 217, 221-224.

Yellon, S.M. \& Foster, D.L. (1982) Long days are required to initiate and sustain ovulatory cycles under short days in the lamb. Endocrinology 110, Suppl., Abstr. 178.

Received 25 March 1983 